\title{
Ethanol Experience Enhances Glutamatergic Ventral Hippocampal Inputs to D1 Receptor-Expressing Medium Spiny Neurons in the Nucleus Accumbens Shell
}

\author{
Daniel M. Kircher, ${ }^{\oplus}$ Heather C. Aziz, ${ }^{\circ}$ Regina A. Mangieri, ${ }^{*}$ and Richard A. Morrisett ${ }^{\star \dagger}$ \\ College of Pharmacy, University of Texas at Austin, Austin, Texas 78712
}

\begin{abstract}
A growing number of studies implicate alterations in glutamatergic signaling within the reward circuitry of the brain during alcohol abuse and dependence. A key integrator of glutamatergic signaling in the reward circuit is the nucleus accumbens, more specifically, the dopamine D1 receptor-expressing medium spiny neurons (D1-MSNs) within this region, which have been implicated in the formation of dependence to many drugs of abuse including alcohol. D1-MSNs receive glutamatergic input from several brain regions; however, it is not currently known how individual inputs onto D1-MSNs are altered by alcohol experience. Here, we investigate input-specific adaptations in glutamatergic transmission in response to varying levels of alcohol experience. Virally mediated expression of Channelrhodopsin in ventral hippocampal (vHipp) glutamate neurons of male mice allowed for selective activation of vHipp to D1-MSN synapses. Therefore, we were able to compare synaptic adaptations in response to low and high alcohol experience in vitro and in vivo. Alcohol experience enhanced glutamatergic activity and abolished LTD at vHipp to D1-MSN synapses. Following chronic alcohol experience, GluA2-lacking AMPARs, which are Ca permeable, were inserted into vHipp to D1-MSN synapses. These findings support the reversal of alcohol-induced insertion of Ca-permeable AMPARs and the enhancement of glutamatergic activity at vHipp to D1-MSNs as potential targets for intervention during early exposure to alcohol.
\end{abstract}

Key words: alcohol use disorders; electrophysiology; nucleus accumbens; optogenetics; plasticity; ventral hippocampus

Significance Statement

Given the roles of the nucleus accumbens (NAc) in integrating cortical and allocortical information and in reward learning, it is vital to understand how inputs to this region are altered by drugs of abuse such as alcohol. The strength of excitatory inputs from the ventral hippocampus (vHipp) to the NAc has been positively associated with reward-related behaviors, but it is unclear whether or how ethanol affects these inputs. Here we show that vHipp-NAc synapses indeed are altered by ethanol exposure, with vHipp glutamatergic input to the NAc being enhanced following chronic ethanol experience. This work provides insight into ethanol-induced alterations of vHipp-NAc synapses and suggests that, similarly to drugs such as cocaine, the strengthening of these synapses promotes reward behavior.

\section{Introduction}

Chronic exposure to drugs of abuse and alcohol induces several forms of metaplasticity within the nucleus accumbens (NAc)

Received Dec. 4, 2018; revised Jan. 11, 2019; accepted Jan. 15, 2019.

Author contributions: D.M.K. wrote the first draft of the paper; D.M.K., H.C.A., R.A. Mangieri, and R.A. Morrisett edited the paper; D.M.K. and R.A. Morrisett designed research; D.M.K. and H.C.A. performed research; D.M.K. and R.A. Mangieri analyzed data; D.M.K. wrote the paper.

This work was supported by the National Institute on Alcohol Abuse and Alcoholism (Grants AA015167 and AA016651, to R.A. Morrisett) and by Homer Lindsey Bruce and Fred Murphy Jones endowed graduate fellowships to D.M.K. We thank Daniela Carrizales for assistance with animal behavior and Paul Slesinger for critical review of the manuscript.

Conflict of Interest: Dr. Kircher reports no financial interests or potential conflicts of interest. Aziz MSc, reports no financial interests or potential conflicts of interest. Dr. Mangieri reports no financial interests or potential conflicts of interest. The authors of this manuscript are unaware of any financial interest or potential conflicts of interest for Dr. Morrisett whom retains senior authorship of this manuscript posthumously.
(Lüscher and Malenka, 2011; McCool, 2011). For example, several groups have shown that chronic exposure to psychostimulants, heroin, or alcohol alters the expression of NMDARdependent LTD in the NAc (Thomas et al., 2001; Martin et al., 2006; Kasanetz et al., 2010; Abrahao et al., 2013; Shen and Kalivas, 2013; Jeanes et al., 2014; Spiga et al., 2014; Renteria et al., 2018). Alterations in accumbal synaptic plasticity likely play a critical

\footnotetext{
${ }^{*}$ R. Mangieri and R. Morrisett were co-senior authors.

${ }^{\dagger}$ Deceased.

D.M. Kircher's present address: Icahn School of Medicine at Mount Sinai, New York, New York, 10029.

Correspondence should be addressed to Regina A. Mangieri at reginamangieri@utexas.edu or Daniel M. Kircher atdmkircher@gmail.com.

https://doi.org/10.1523/JNEUROSCI.3051-18.2019

Copyright $\odot 2019$ the authors $\quad 0270-6474 / 19 / 392459-11 \$ 15.00 / 0$
} 
role in the formation of dependence on various drugs of abuse including alcohol.

Previously, we demonstrated that chronic intermittent ethanol (CIE) vapor exposure enhances the excitability of dopamine D1 receptor-expressing medium spiny neurons (D1-MSNs) and increases NMDAR activity in D1-MSNs (Renteria et al., 2017). CIE reliably induces enhancements in volitional ethanol intake (Becker and Lopez, 2004; Jeanes et al., 2011; Renteria et al., 2018). Interestingly, CIE vapor exposure also disrupts glutamatergic synaptic depression in the NAc and does so in a manner that is dependent on the subtype of MSN and strain of mouse (Jeanes et al., 2014; Renteria et al., 2017). Therefore, as we have stated previously (Renteria et al., 2016), ethanol-induced alterations in glutamatergic synaptic plasticity (i.e., metaplasticity) within the D1-MSNs of the NAc may be critically related to the expression of ethanol drinking behavior, with enhanced glutamatergic activity within the NAc following CIE exposure leading to a high drinking phenotype compared with animals that do not exhibit such alterations.

Recently, we reported that CIE induced escalation in drinking in $\mathrm{C} 57 \mathrm{BL} / 6 \mathrm{~J}$ mice produced a disruption in the NAc shell (shNAc) D1-MSN plasticity that mirrored the time course of escalated drinking observed following CIE exposure (Becker and Lopez, 2004; Renteria et al., 2018). The disrupted plasticity was accompanied by an increase in the rectification index of AMPARmediated currents in D1-MSNs of the shNAc $24 \mathrm{~h}$ after the last drinking session. The presence of rectification suggested synaptic insertion of GluA2 subunit-lacking AMPARs, which are Ca permeable. Changes in rectification as well as insertion of Capermeable AMPARs into the synapse have been observed following withdrawal from cocaine administration (Loweth et al., 2014; Scheyer et al., 2014). Insertion of Ca-permeable AMPARs into shNAc D1-MSN synapses following repeated drug exposure likely plays a role in relapse following periods of withdrawal, as well as in the escalation of drug intake observed following repeated use, and may play a role in the loss of LTD expression.

Recent studies with psychostimulants indicate that drug exposure produces selective effects on different glutamatergic inputs to the NAc (Pascoli et al., 2011, 2014; Stuber et al., 2012; Joffe and Grueter, 2016). Here, we designed a study to characterize neuroadaptations in a specific glutamatergic input to the shNAc with excessive ethanol consumption. The NAc receives major inputs from the hippocampal ventral subiculum (Groenewegen et al., 1987) and the ventral CA1 (Britt et al., 2012). Furthermore, the NAc requires hippocampal stimulation for depolarization and transition into an activated state (O'Donnell and Grace, 1995). Information from the hippocampus is involved in mediating drug-seeking behaviors (Fuchs et al., 2005; Riaz et al., 2017), with lesions altering Pavlovian-conditioned approach behaviors (Fitzpatrick et al., 2016) possibly due to disrupting gating and outflow of NAc signals (French and Totterdell, 2002). Inactivation of the ventral CA1 region selectively inhibits cocaine seeking without disrupting food seeking or locomotor behavior (Rogers and See, 2007; Lasseter et al., 2010). Last, potentiation of vHippNAc synapses can promote reward-related behavior (LeGates et al., 2018). To our knowledge, there is no published research regarding the impact of ethanol exposure on the vHipp-NAc shell pathway. Therefore, we used optogenetics to selectively stimulate vHipp inputs to genetically defined D1-MSNs in the shNAc to determine whether excessive alcohol consumption alters AMPARmediated signaling and disrupts NMDAR LTD in this important glutamatergic projection to the shNAc.

\section{Materials and Methods}

Procedures and mice. All procedures were approved by the Institutional Animal Care and Use Committee of The University of Texas at Austin. Mice were hemizygous BAC-transgenic mice in which tdTomato fluorophore expression was driven by dopamine D1 receptor gene regulatory elements; B6.Cg-Tg(Drdla-tdTomato)6Calak/J (Ade et al., 2011). Drd1a-tdTomato breeding pairs were previously obtained from The Jackson Laboratory (stock no. 016204) and this line was maintained at the University of Texas at Austin by mating hemizygous mice with noncarrier Drd1a-tdTomato mice (or periodic backcrossing with C57BL/6J mice). All mice were kept in a temperature- and humidity-controlled environment with a $12 \mathrm{~h}$ light/12 h dark cycle (lights off at $0930 \mathrm{~h}$ ). All procedures were approved by the Institutional Animal Care and Use Committee of the University of Texas at Austin.

Stereotaxic injections. AAV2-CaMKIIa-hChR2(H134R)-eYFP or AAV2CaMKIIa-eYFP (for control mice) produced at the University of North Carolina Vector Core Facility was injected into the vHipp of 5- to 6-week-old male mice. Anesthesia was induced at $3 \%$ and maintained at a range of $1.5-2 \%$ isoflurane (w/v) (Animal Health International). Mice were placed in a stereotaxic frame (Kopf Instruments) and bilateral craniotomies were performed using stereotaxic coordinates adapted from a mouse brain atlas (Paxinos and Franklin, 2001) (anterior-posterior $=-2.8$; medial-lateral $=$ \pm 2.8 ; dorsal-ventral from the surface of the brain $=-4.2)$. Injections of virus ( $0.55 \mu \mathrm{l}$ per injection site) were made using a Nanoject II with pulled glass pipettes (Drummond Scientific) broken back to a tip diameter of 10-15 $\mu \mathrm{m}$ at an infusion rate of $\approx 0.05 \mu \mathrm{l} / \mathrm{s}$.

Two-bottle choice $(2 B C)$ and air/ethanol vapor exposure. Two weeks after virus injections, mice began 21 consecutive days of $2 \mathrm{BC}$ drinking, a limited access $(2 \mathrm{~h})$ paradigm used to measure volitional ethanol consumption (Griffin, 2014). Thirty minutes before the beginning of the dark cycle (lights out at $0930 \mathrm{~h}$ ), mice were given access to two bottles, one containing a $15 \%$ ethanol and tap water solution and the other containing tap water alone. Animals and bottles were weighed before $2 \mathrm{BC}$ and bottles were weighed again after $2 \mathrm{~h}$ access. The difference in bottle weights was used to calculate the dose of ethanol consumed as grams of ethanol (difference in ethanol bottle weights ${ }^{*} 0.12$ ) per kilogram animal body weight per $2 \mathrm{~h}$. The last $5 \mathrm{~d}$ of this drinking period was measured as baseline ethanol consumption.

Following this $21 \mathrm{~d}$ of drinking, animals underwent CIE vapor (or air) exposure (Becker and Lopez, 2004). Mice were exposed to ethanol vapor following an injection with a loading dose of ethanol $(20 \% \mathrm{v} / \mathrm{v}, 1.5 \mathrm{~g} / \mathrm{kg}$, i.p.) and pyrazole $(68.1 \mathrm{mg} / \mathrm{kg}$, i.p.) suspended in $0.1 \mathrm{~m}$ PBS. Air-exposed animals received an injection of pyrazole but not ethanol. Ethanol was volatilized by bubbling air through a flask containing $95 \%$ ethanol at a rate of $3.5 \mathrm{~L} / \mathrm{min}$. Ethanol vapor was then combined with a separate air stream to give a total flow rate of $\sim 4 \mathrm{~L} / \mathrm{min}$. Ethanol enriched air (or air alone for the air group) was pumped into special mouse chamber units with airtight tops (Allentown). Each CIE bout consisted of 4 consecutive days of exposure for $16 \mathrm{~h}$ followed by $8 \mathrm{~h}$ of withdrawal. Following each $16 \mathrm{~h}$ exposure session, the blood ethanol concentrations (BEC) were analyzed from tail blood by samples by gas chromatograph (Bruker model \#430-GC). Target BECs following each session were between 150 and $200 \mathrm{mg} / \mathrm{dl}(37-47 \mathrm{~mm}$ ). BECs were maintained by adjusting the flow rate and the loading dose of ethanol and pyrazole. Additional details regarding BEC analysis was described previously (Renteria et al., 2018). After the conclusion of each $4 \mathrm{~d}$ bout of CIE or air exposure, animals were returned to their home cages for $72 \mathrm{~h}$ of withdrawal. After withdrawal, $2 \mathrm{BC}$ drinking was conducted for $5 \mathrm{~d}$ to measure CIE-induced changes in ethanol consumption.

Brain slice preparation. Parasagittal slices (230-240 $\mu \mathrm{m}$ thick) containing the shNAc were prepared using a Leica vibrating microtome. For ethanol-exposed mice, slices were prepared $\sim 24 \mathrm{~h}$ after the last drinking session ( $\sim 2 \mathrm{~h}$ into the dark phase of the light cycle); slices were prepared from ethanol naive mice around this same time of day. Mice were anesthetized by inhalation of isoflurane and the brains were rapidly removed and placed in $4^{\circ} \mathrm{C}$ oxygenated artificial CSF (ACSF) containing the following in (mM): 210 sucrose, $26.2 \mathrm{NaHCO}_{3}, 1 \mathrm{NaH}_{2} \mathrm{PO}_{4}, 2.5 \mathrm{KCl}, 11$ dextrose $6 \mathrm{MgSO}_{4}$, and $2.5 \mathrm{CaCl}_{2}$, bubbled with $95 \% \mathrm{O}_{2} / 5 \% \mathrm{CO}_{2}$. For 
incubation, slices were transferred to a non-sucrose-based ACSF solution containing the following (in $\mathrm{mm}$ ): $120 \mathrm{NaCl}, 25 \mathrm{NaHCO}_{3}, 1.23$ $\mathrm{NaH}_{2} \mathrm{PO}_{4}, 3.3 \mathrm{KCl}, 2.4 \mathrm{MgSO}_{4}, 1.8 \mathrm{CaCl}_{2}$, and 10 dextrose continuously bubbled with $95 \% \mathrm{O}_{2} / 5 \% \mathrm{CO}_{2}, \mathrm{pH} 7.4,32^{\circ} \mathrm{C}$, and were maintained in this solution for at least $60 \mathrm{~min}$ before recording.

Patch-clamp electrophysiology. Whole-cell voltage-clamp recordings were conducted in the medial shNAc. Cells were identified using a BX50 microscope (Olympus) mounted on a vibration isolation table. Recordings were made in ACSF containing the following (in $\mathrm{mM}$ ): $120 \mathrm{NaCl}, 25$ $\mathrm{NaHCO}_{3}, 1.23 \mathrm{NaH}_{2} \mathrm{PO}_{4}, 3.3 \mathrm{KCl}, 0.9 \mathrm{MgSO}_{4}, 2.0 \mathrm{CaCl}_{2}$, and 10 dextrose bubbled with $95 \% \mathrm{O}_{2} / 5 \% \mathrm{CO}_{2}$. ACSF was continuously perfused at a rate of $2.0 \mathrm{ml} / \mathrm{min}$ and maintained at a temperature of $\approx 32^{\circ} \mathrm{C}$. Picrotoxin $(50 \mu \mathrm{M})$ was included in the recording ACSF to block $\mathrm{GABA}_{\mathrm{A}} \mathrm{R}$-mediated synaptic currents. The NMDAR antagonist APV (50 $\mu \mathrm{M}$; Tocris Bioscience) was added to the recording solution for rectification index (RI) recordings to isolate AMPAR-mediated currents. Strontium chloride ( $\mathrm{SrCl}_{2}, 6 \mathrm{~mm}$; Tocris Bioscience) was substituted for $\mathrm{CaCl}_{2}$ in the recording solution for asynchronous EPSC (asEPSC) recordings. 1-Naphthyl acetyl spermine trihydrochloride (NASPM, $100 \mu \mathrm{M}$; Tocris Bioscience), the selective antagonist for GluA2 subunit lacking AMPARs (Capermeable AMPARs), was added to the recording solution in a subset of recordings to verify Ca-permeable AMPAR insertion. Recording electrodes (thin-wall glass, 1.5 outer diameter/1.12 inner diameter; WPI) were made using a Brown-Flaming model P-97 electrode puller (Sutter Instruments) to yield resistances between 3 and $6 \mathrm{M} \Omega$. Electrodes were filled with either a potassium based solution containing the following (in mM): $135 \mathrm{KMeSO} 4,12 \mathrm{NaCl}, 0.5$ EGTA, 10 HEPES, $2 \mathrm{Mg}$-ATP, and 0.3 Tris-GTP [for spontaneous EPSC (sEPSC) and some LTD recordings] or a cesium-based solution containing the following (in $\mathrm{mM}$ ): 120 CsMeSO4, $15 \mathrm{CsCl}, 8 \mathrm{NaCl}, 10$ HEPES, 0.2 EGTA, 10 TEA-Cl, 4 MgATP, 0.3 Na-GTP, 0.1 spermine, and 5 QX-314-Cl (for, AMPA/NMDA ratio, asEPSC, RI, NASPM, and some LTD recordings). Chemicals were obtained from Sigma-Aldrich or Fisher Scientific unless otherwise noted.

Electrophysiology data acquisition. Whole-cell voltage-clamp recordings were conducted on shNAc D1-MSNs surrounded by ChR2expressing terminals identified by epifluorescent illumination of tdTomato and eYFP. EPSCs were acquired using an amplifier (PC-One; Dagan) filtered at $1 \mathrm{kHz}$ and digitized at $10-20 \mathrm{kHz}$ with a Digidata 1440B interface board using pClamp 10.6 (Molecular Devices). A blue light LED (465 nm; Plexon) was coupled to the objective via a fiber coupler (IS-OGP/OLY, Siskiyou). Following the acquisition of the whole-cell configuration, D1-MSNs were held at $-80 \mathrm{mV}$ and oEPSCs were evoked with $4 \mathrm{~ms}$ blue light pulses. Light intensity was adjusted for each recording to elicit oEPSCs in a range from 150 to $300 \mathrm{pA}$. In experiments for long term plasticity, oEPSCs were evoked every $15 \mathrm{~s}$ for at least $10 \mathrm{~min}$. To induce LTD, a conditioning stimulus of 500 light pulses (4 $\mathrm{ms})$ at $1 \mathrm{~Hz}$ was paired with continuous postsynaptic depolarization from $-80 \mathrm{mV}$ to $-50 \mathrm{mV}$. oEPSCs were then monitored for $30 \mathrm{~min}$ after pairing. The magnitude of LTD was calculated by averaging normalized (to baseline) oEPSC values from 20 to $30 \mathrm{~min}$ after pairing and comparing that with the average normalized oEPSCs during the $10 \mathrm{~min}$ baseline. Our criterion for the expression of plasticity required that the difference between averaged oEPSCs from the baseline and after pairing be $>2$ SDs. Correlations between the amount of ethanol consumed $(\mathrm{g} / \mathrm{kg})$ in the last drinking session and the magnitude of LTD (\% baseline) were tested using the nonparametic Spearman's rank order test. sEPSCs were recorded for 3 min separated into 20 consecutive sweeps 10 min after achieving whole-cell configuration. Events $>5 \mathrm{pA}$ were included for analysis using Clampfit version 10.6. asEPSCs were evoked by blue light stimulation in the presence of $\mathrm{SrCl}_{2}$. Analysis of asEPSCs began $30 \mathrm{~ms}$ after stimulus offset up to $400 \mathrm{~ms}$. Frequency and average amplitude of sEPSCs and asEPSCs were determined using Clampfit Template Search. Paired-pulse ratios (PPRs) were acquired by applying two stimuli of equal intensity separated by an ISI of $50 \mathrm{~ms}$ and calculated as a ratio of oEPSC 2/oEPSC 1. NMDA/AMPA ratios were calculated as the ratio of the oEPSC recorded at $+40 \mathrm{mV}, 50 \mathrm{~ms}$ after afferent stimulation (NMDA) and the peak oEPSC recorded at $-80 \mathrm{mV}$ (AMPA). NMDAR currents were recorded at $+40 \mathrm{mV}$ and were pharmacologically isolated using $50 \mu \mathrm{M}$ picrotoxin, $10 \mu \mathrm{M}$ DNQX, and $1 \mu \mathrm{M}$ CGP 52432. For RI recordings, a current-voltage plot was generated measuring AMPARmediated currents at the following holding potentials (in $\mathrm{mV}$ ): -80 , $-40,0,+20$, and +40 . The RI was determined as the ratio of oEPSC amplitudes at +40 and $-80 \mathrm{mV}$. For all recordings, membrane and access resistances were monitored throughout the experiments. Cells in which access resistance varied $>35 \%$ were not included in analysis. The maximum access resistance allowed for recordings was $35 \mathrm{M} \Omega$.

Experimental design and statistical analysis. For acute experiments (see Figs. 1,2), all mice were ethanol naive and at least 10 weeks of age by the time experiments were conducted (allowing $\geq 5$ weeks for virally mediated expression of ChR2/eYFP in vHipp axon terminals). For the in vivo ethanol experience experiments (see Figs. 3, 4, 5, 6), a limited-access 2BC drinking procedure was used to establish baseline alcohol consumption in ChR2-eYFP virus-injected mice interspersed with three cycles of CIE vapor (2BC:Vapor group) or air (2BC:Air group) exposure, each followed by $2 \mathrm{BC}$ drinking to determine CIE-induced changes in ethanol consumption (see Fig. 3A) (Renteria et al., 2018). Control mice (AAV2CaMKIIa-eYFP) expressing eYFP alone underwent identical procedures as the ChR2-eYFP-expressing groups, with half being exposed to ethanol vapor and half to air (eYFP:Vapor and eYFP:Air groups, respectively). Ethanol-naive mice expressing ChR2 in the vHipp were used for comparison with the in vivo ethanol-exposed mice. For the experiments shown in Figures 4, 5, and 6, recordings from these ethanol- and behaviorally naive mice were interspersed with the ethanol-exposed mice and mice were approximately the same age at the time of recording.

Statistical analysis was performed in Prism version 5 software (GraphPad) unless otherwise noted. Statistical significance was defined as $p<0.05$. For experiments with only two groups (Figs. $1 D, 5 D, 6 D$ ), differences were evaluated using unpaired Student's $t$ test. For experiments comparing three levels of a between-groups factor (Figs. $2 C, 3 D, 4 B, D, 5 B, 6 B$ ), one-way ANOVA with Bonferroni post hoc tests were used. For the data shown in Figure $3 E$, correlations between ethanol consumed and the magnitude of LTD were evaluated using Spearman's correlation.

For the experiment shown in Figure 3B, ethanol consumption data were analyzed using the general linear model repeated-measures procedure in SPSS Statistics 23, with a $4 \times 5$ by $2 \times 2$ design. The two repeated measures were period ( 4 levels: baseline 2BC, 2BC:1, 2BC:2, 2BC:3) and day within each period ( 5 levels) and the between-group factors being virus (eYPF vs ChR2-eYFP) and treatment (Air vs Vapor). This analysis revealed a statistically significant period $\times$ treatment interaction, which was investigated by analyzing the simple effects of period for each treatment group and treatment group for each period using the method described by Kirk (1982). Greenhouse-Geisser-corrected degrees of freedom and $p I$-values are reported due to violations of sphericity within the repeated measures (as indicated by Mauchly's test). The simple effect of period in the vapor group was further analyzed by pairwise comparisons using the Bonferroni adjustment.

\section{Results}

\section{vHipp glutamatergic input to shNAc is capable of expressing NMDAR-LTD}

To study excitatory inputs from vHipp to D1-MSNs in shNAc, we injected AAV2-CaMKIIa-hChR2(H134R)-eYFP into the vHipp of male Drdla-tdTomato mice. After 13 weeks, we detected ChR2-eYFP expression in vHipp neurons and in terminals present in the shNAc (Fig. 1 $A, B$ ). Prior studies indicated that photoactivation of ChR2 in glutamatergic terminals is sufficient for eliciting EPSCs in MSNs as well as eliciting plasticity (Britt et al., 2012; Pascoli et al., 2014). Consistent with this, blue light (465 $\mathrm{nm}, 4 \mathrm{~ms}$ pulses) reliably evoked EPSCs in D1-MSNs (oEPSCs) (Fig. 1B). Previously, electrical stimulation could induce NMDAR-dependent LTD in D1-MSNs of the shNAc (Jeanes et al., 2014; Renteria et al., 2018). To examine possible LTD of excitatory vHipp inputs, we combined light stimulation (4 ms pulses at $1 \mathrm{~Hz}$ for 500 sweeps) with postsynaptic membrane depolarization to $-50 \mathrm{mV}$. Pairing ( $500 \mathrm{~s}$ ) was sufficient to produce LTD of oEPSC amplitudes (Fig. 1C,D). Extracellular perfusion of 
A
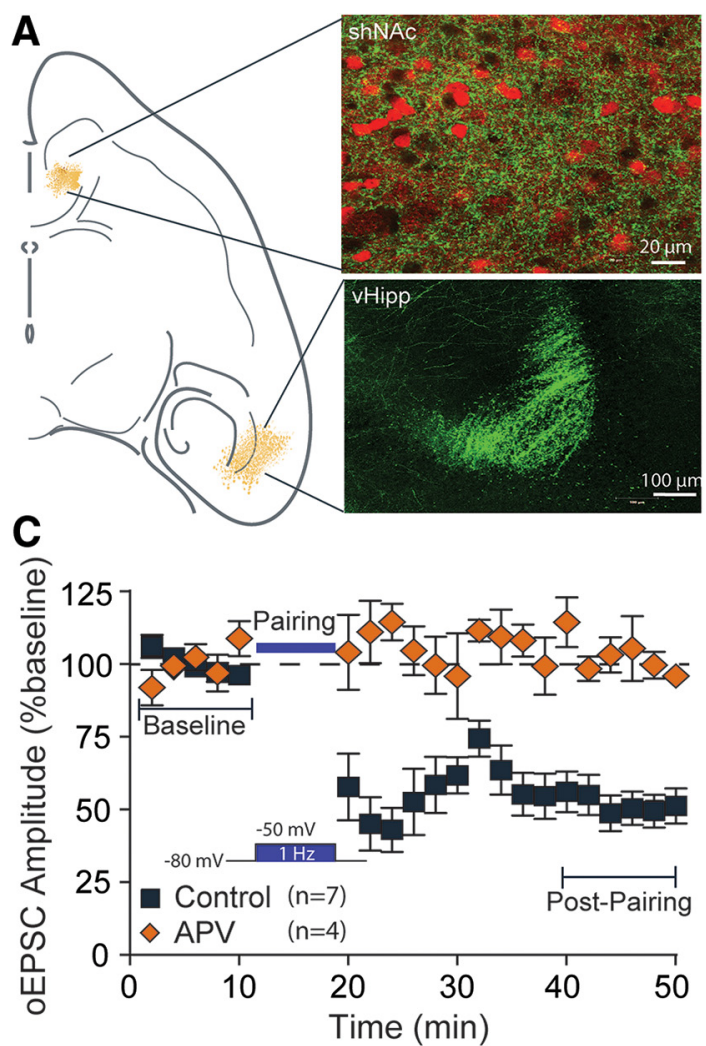

B
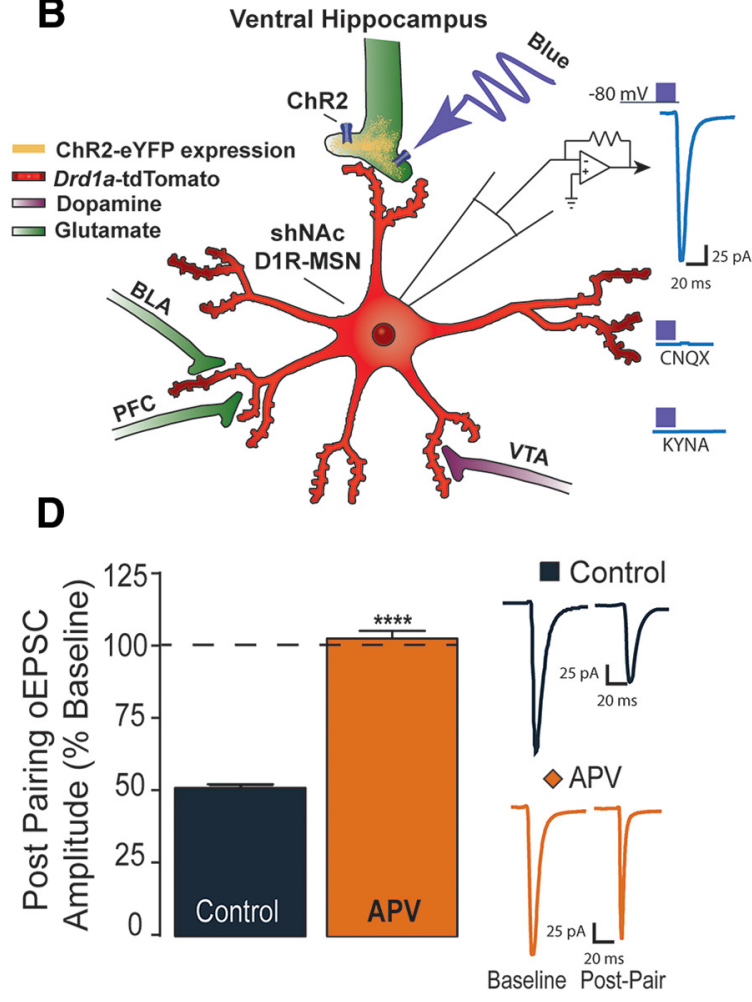

Figure 1. Optical low-frequency stimulation paired with membrane depolarization of D1-MSNs induces NMDAR-LTD in vHipp-shNAc circuit. A, Injection of AAV2-CaMKII-ChR2-eYFP into vHipp resulted in eYFP expression in vHipp glutamatergic neurons and in the terminals within the NAcshell. D1-MSNs were visualized by tdTomato fluorescence. $\boldsymbol{B}$, Whole-cell patch-clamp recordings were conducted in D1-MSNs and oEPSCs were elicited by blue light activation of ChR2 present in vHipp terminals within the NAc shell. oEPSCs are AMPAR dependent and were abolished in the presence of the AMPAR antagonist CNQX or the nonselective antagonist kynurenic acid (KYNA). C, A pairing protocol consisting of $1 \mathrm{~Hz}$ light stimulation (500 s) of vHipp terminals paired with postsynaptic membrane depolarization from -80 to $-50 \mathrm{mV}$ resulted in LTD of vHipp oEPSCs in D1-MSNs. The inclusion of the NMDAR antagonist D-APV in the bath prevented LTD expression. D, Bar graphs representing average oEPSC amplitudes as a percentage of baseline \pm SEM during the ostpairing period $(\min 40-50)$. Student's $t$ test: $t_{(9)}=6.3,{ }^{* * * *} p=0.0001 \mathrm{APV}$ vs control (control: $51.19 \pm$ $5.73 n=7$ cells from 6 mice; APV: $102.6 \pm 3.59, n=4$ cells from 4 mice).

the NMDAR antagonist APV $(50 \mu \mathrm{M})$ before and during the optical pairing protocol prevented the expression of LTD (Fig. $1 C, D)$, confirming this form of optically induced plasticity is dependent on the activation of NMDARs.

\section{Acute in vitro ethanol exposure inhibits vHipp-NAc glutamatergic plasticity}

Acute ethanol can inhibit NMDARs (Martin et al., 1991; Thomas et al., 1998; Hendricson et al., 2004) and alter the expression of LTD in the NAc (Jeanes et al., 2011, 2014, Renteria et al., 2017, 2018). We therefore examined the effect of acute ethanol on optically evoked LTD of the vHipp input to shNAc D1-MSNs. Bath application of a moderately to strongly intoxicating concentration of ethanol ( $40 \mathrm{mM})$, equivalent to $\approx 0.2$ blood alcohol concentration, completely inhibited LTD expression (Fig. 2A,B). Bath application of a low intoxicating concentration of ethanol (20 mM), equivalent to $\approx 0.1$ blood alcohol concentration, also prevented induction of LTD (Fig. $2 A, B$ ). We observed a significant difference in the average postpairing oEPSC amplitude between both ethanol treatment groups and the ethanol-naive control group, with the ethanol-naive cells exhibiting robust reduction in oEPSC amplitude and little or no change in amplitude in the ethanol-exposed cells (Fig. 2D). A significant reduction in oEPSC amplitudes in the $20 \mathrm{~mm}$ ethanol-exposed cells contrasts with our previous report using electrical stimulation, where we did not observe a disruption of LTD at this concentration of ethanol (Jeanes et al., 2011).

\section{CIE vapor exposure induces escalation of volitional ethanol} intake in mice

Our in vitro findings suggest that the vHipp-shNAc circuit is sensitive to acute ethanol exposure. To examine the neural adaptations produced by in vivo ethanol exposure within this circuit, animals were given free access to consume ethanol and were then subjected to either ethanol vapor or air exposure. Two weeks after stereotaxic injection of the viral vector for ChR2-eYFP or control-eYFP, mice were subjected to daily, limited access 2BC drinking for $21 \mathrm{~d}$ before the first vapor (or air control) exposure (for details, see Fig. 3A). The last $5 \mathrm{~d}$ of drinking were measured as the baseline of consumption and the dose of ethanol consumed during the baseline was not different between the air $(1.51 \pm 0.04$ $\mathrm{g} / \mathrm{kg}$ ) and ethanol vapor $(1.56 \pm 0.07 \mathrm{~g} / \mathrm{kg}$ ) groups (simple effect of treatment group during baseline: $F_{(1,59)}=0.03, p=0.8638$ ). As expected, CIE vapor, but not air, exposure resulted in an escalation in ethanol consumption (Fig. 3B). We did not observe any evidence that the type of virus injected (ChR2-eYFP or eYFP) influenced drinking behavior or the escalation of drinking by CIE vapor; there was no main effect of virus $\left(F_{(1,33)}=0.501, p=\right.$ $0.484)$, no virus by treatment group interaction $\left(F_{(1,33)}=0.413\right.$, $p=0.525)$, no virus by drinking period interaction $\left(F_{(2.4,78.8)}=\right.$ $0.31, p=0.772$ ), and no virus by treatment group by drinking period interaction $\left(F_{(2.4,78.8)}=0.27, p=0.804\right)$. The CIE vapor induced increase in volitional ethanol consumption mirrors that we previously reported (Renteria et al., 2018). 


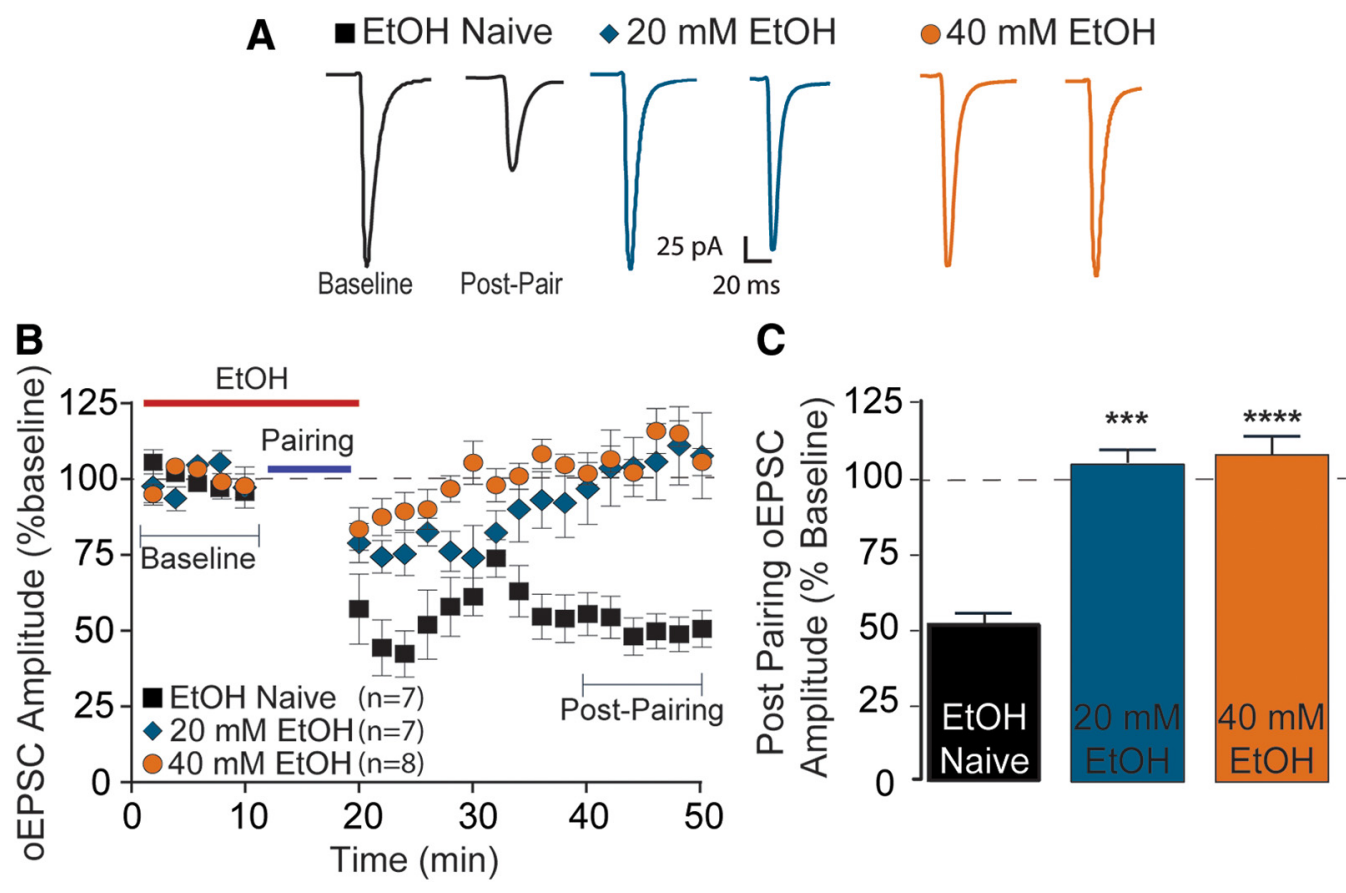

Figure 2. Acute in vitro ethanol exposure abolishes the expression of glutamatergic plasticity of vHipp-shNAcD1-MSNs. Escalating concentrations of ethanol applied in vitro in the recording bath disrupt the expression of NMDAR-LTD. $A$, Sample traces of averaged baseline and postpairing oEPSCS ( 40 sweeps, $10 \mathrm{~min}$ ) of a single representative recording from each group. $B$, A pairing protocol elicited LTD in ethanol-naive neurons. A total loss of LTD expression was observed during exposure to low $(20 \mathrm{~mm})$ and moderate $(40 \mathrm{~mm})$ concentrations of ethanol. $C$, Bar graphs representing average oEPSC amplitudes as a percentage baseline \pm SEM during postpairing period $(\min 40-50)$ (EtOH naive: $51.19 \pm 5.73, n=7$ cells from 6 mice; $20 \mathrm{mm:} 105 \pm 11.47, n=7$ cells from 4 mice; 40 mm: $108.1 \pm 2.49, n=8$ cells from 6 mice). ANOVA: $F_{(2,19)}=19.25, p<0.0001$. Bonferroni post hoc tests: ${ }^{* * *} p<0.001,20$ mm Et0H vs naive; ${ }^{* * * *} p<0.0001,40$ mm Et0H vs naïve).

\section{Ethanol consumption and CIE-induced escalation of intake are accompanied by disrupted vHipp-NAc glutamatergic plasticity}

Previous studies have shown that NMDAR-dependent plasticity is disrupted after in vivo drug or ethanol exposure (Brebner et al., 2005; Kasanetz et al., 2010; Pascoli et al., 2011; Abrahao et al., 2013). Here, we investigated whether induction of LTD in D1MSNs of the vHipp-shNAc circuit was affected by prior exposure to escalating ethanol intake.

In ethanol vapor-treated mice, NMDAR-LTD in the vHippshNAc circuit did not develop with pairing of optical stimulation and postsynaptic depolarization (Fig. 3C,D). In 2BC air-exposed mice, NMDAR-LTD was expressed but was reduced compared with ethanol naive control animals (Fig. 3C,D). We also observed that the amount of ethanol consumed during the last $2 \mathrm{~h}$ drinking session was correlated with the magnitude of LTD. Recordings from air-exposed mice showed a significant inverse relationship between ethanol consumption and the magnitude of LTD. Interestingly, recordings from vapor-exposed animals showed no correlation; however, there was an overall correlation between the amount of ethanol consumed and the magnitude of LTD when vapor-exposed, air-exposed, and ethanol-naive mice were analyzed (Fig. 3E). These findings suggest that the amount of ethanol consumed, in the absence of vapor exposure, opposes the expression of vHipp-shNAc NMDAR-LTD.

\section{Ethanol consumption is associated with enhanced} vHipp-NAc glutamatergic signaling

Previously, Renteria et al. (2018) showed ethanol consumption and CIE vapor exposure enhances sEPSC frequency $24 \mathrm{~h}$ after the last drinking session (Renteria et al., 2018). Here, we measured both the frequency and amplitude of sEPSCs. In ethanol vapor- exposed mice, sEPSC frequency and amplitude were increased $24 \mathrm{~h}$ after the last drinking session (Fig. $4 A, B$ ).

To examine circuit-specific adaptations in glutamatergic signaling, we took advantage of ChR2 expression in vHipp terminals and used blue light stimulation to evoke quantal like events from vHipp terminals in the presence of strontium (asEPSC). Replacing calcium with strontium in the extracellular solution prolongs release events and results in quantal-like release events occurring for a short duration following stimulation (analysis began $30 \mathrm{~ms}$ after stimulus offset and ended at $400 \mathrm{~ms}$ ) (Gerdeman and Lovinger, 2001). Circuit-specific analysis of glutamatergic signaling revealed a significant increase in asEPSC frequency in the vapor-treated group compared with naive animals (Fig. $4 C, D$ ), suggesting that vapor exposure and an escalation in ethanol consumption leads to a presynaptic alteration in glutamatergic signaling. We noted a significant effect of ethanol consumption on asEPSC amplitude. Post hoc analysis indicates a significant increase in asEPSC amplitude in the air treated group compared with naive, as well as significant increase in asEPSC amplitude in the vapor-exposed group compared with naive and air-exposed animals (Fig. 4C,D). These findings suggest that ethanol consumption is enhancing postsynaptic glutamatergic function at D1-MSNs synapses with the vHipp, with the largest enhancement in asEPSCs occurring following escalation in consumption produced by CIE vapor exposure.

Considering the observed alterations in asEPSC amplitude and frequency, we attempted to recapitulate the presynaptic effect by measuring PPRs (2 pulses, $50 \mathrm{~ms}$ ISI), which are inversely correlated with neurotransmitter release. We observed that ethanol consumption produced a decrease in the PPR (oEPSC 2/oEPSC 1) (Fig. 5A,B). Post hoc analysis indicated a significant reduction in PPR in both air- and vapor-treated groups relative to 


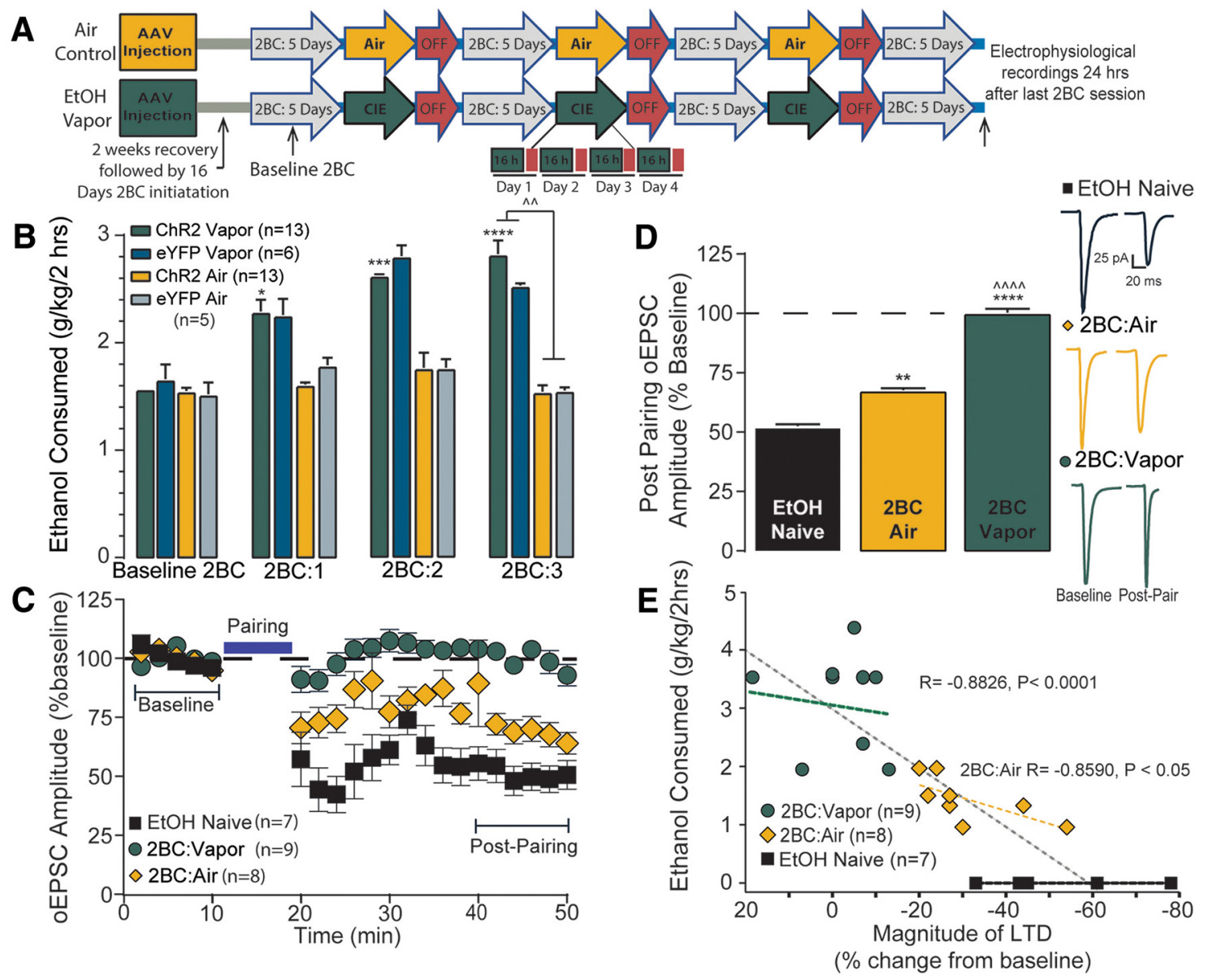

Figure 3. In vivo ethanol exposure is associated with disrupted glutamatergic plasticity of vHipp-shNAc D1-MSNs. A, CIE exposure consisted of 3 bouts of ethanol vapor (or air control) exposure separated by $3 \mathrm{~d}$ withdrawal and $5 \mathrm{~d} 2 \mathrm{BC}$ drinking (15\% ethanol vs water) periods. Slices were prepared $\sim 24 \mathrm{~h}$ after the last ethanol drinking period. $\boldsymbol{B}$, Average consumption of ethanol $(\mathrm{g} / \mathrm{kg} / 2 \mathrm{~h}) \pm \mathrm{SEM}$ for each $2 \mathrm{BC}$ drinking period. There was a main effect of drinking period $\left(F_{(2389.78 .841)}=10.44 p<0.0001\right)$, with a significant treatment group by drinking period interaction $\left(F_{(2.389,78.841)}=4.37, p=0.011\right)$. Animals exposed to ethanol vapor exhibited an increase in $2 \mathrm{BC}$ drinking over the course of the experiment (simple effect of drinking period: $F_{(3,78.8)}=14.38$, $p<0.0001$ ), whereas no escalation in $2 \mathrm{BC}$ drinking was observed in the air-exposed mice (simple effect of drinking period: $\left.F_{(1.7 .78 .8)}=1.80, p=0.184\right) .{ }^{*} p<0.05$ vs baseline, ${ }^{* * *} p=0.001$, ${ }^{* * * *} p<0.0001$ vs baseline (Bonferroni pairwise comparisons); $\wedge \wedge p<0.01$ vs air (simple effect of group). C, Pairing protocol resulted in LTD in naive animals, but $24 \mathrm{~h}$ after the last drinking session, failed to elicit LTD in the vapor-exposed animals. Relative to ethanol-naïve animals, air-exposed animals exhibited a reduction in LTD magnitude $24 \mathrm{~h}$ after the last drinking period. $\boldsymbol{D}$, Bar graphs representing average EPSC amplitudes as a percentage baseline \pm SEM during the postpairing period $(\min 40-50)$ for each treatment group (Et0H naive: $51.19 \pm 5.73$, Air: $72.03 \pm 2.54$, vapor: $99.86 \pm 2.96 .1 ;$ ANOVA: $F_{(2,21)}=42.31, p<0.0001$. Bonferroni post hoc tests: ${ }^{* *} p<0.01$ vs naive, ${ }^{* * * *} p<0.0001$ vs naive, $\wedge \wedge \wedge \wedge p<0.0001$ vs air; naive $n=7$ cells from 6 mice, air $n=8$ cells from 4 mice, vapor $n=9$ cells from 5 mice. $E$, Inverse correlation between amount ethanol consumed during the last session and the magnitude of LTD observed in the air-exposed animals (Spearman's $r=-0.8590, p<0.05$ ) and an overall negative correlation with LTD magnitude and ethanol exposure (Spearman's $r=-0.8826, p<0.0001$ ).

the ethanol-naive group, suggesting that ethanol consumption leads to an increase in the probability of glutamate release from vHipp terminals onto D1-MSNs of the shNAc. Together, these findings indicate that ethanol consumption enhances glutamatergic signaling in the vHipp-shNAc circuit by reducing LTD and increasing presynaptic release.

\section{CIE does not enhance vHipp-NAc NMDA/AMPA ratio in 2BC-experienced mice}

Previous work demonstrated that the relative activity of NMDA versus AMPARs (as measured by electrically evoked NMDA/ AMPA ratios) is enhanced at shNAc D1-MSN synapses $24 \mathrm{~h}$ after a single $4 \mathrm{~d}$ bout of CIE vapor exposure compared with ethanolnaive air controls (Renteria et al., 2017). Here, we hypothesized that NMDAR activity could be enhanced in vHipp-shNAc D1MSN synapses following the escalation of drinking produced by CIE vapor exposure, but, as shown in Figure 5, $C$ and $D$, NMDA/ AMPA ratios were not significantly different between the 2BC:Air and 2BC:Vapor groups. It should be noted that a change in
NMDAR activity could be masked in this measurement by an accompanying change in AMPAR activity, thereby resulting in no change in the ratio.

\section{Ethanol-consuming mice have a greater proportion of} Ca-permeable AMPARs at vHipp-NAc D1-MSN synapses Insertion of Ca-permeable, rectifying, GluA2-lacking AMPARs occurs following exposure to and withdrawal from psychostimulants (Cull-Candy et al., 2006; Conrad et al., 2008), opiates (Hearing et al., 2016), and ethanol (Beckley et al., 2016; Renteria et al., 2018). Here, we examined the potential change in rectification of vHipp-shNAc AMPARs following ethanol consumption. D1MSNs prepared from mice $24 \mathrm{~h}$ after $2 \mathrm{BC}$ drinking exhibited a rectification of AMPAR oEPSCs at positive holding potentials and an overall decrease in the RI (oEPSC amplitude at $+40 \mathrm{mV}$ / oEPSC amplitude at $-80 \mathrm{mV}$ ) (Fig. $6 A, B$ ). To confirm that the alteration in RI in ethanol-experienced mice was due to the insertion of Ca-permeable AMPARs, we conducted light-evoked current recordings and bath applied the GluA2 subunit-lacking 
A
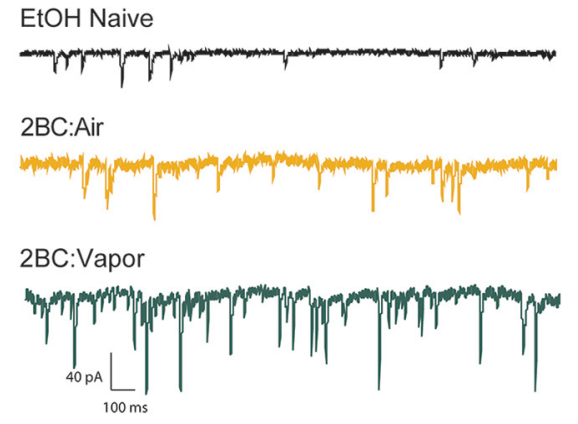

\section{C}
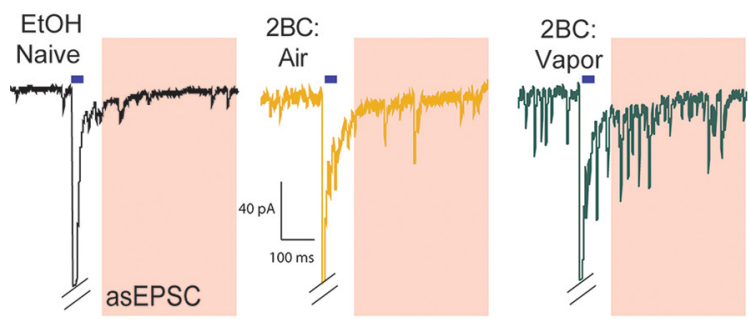

B
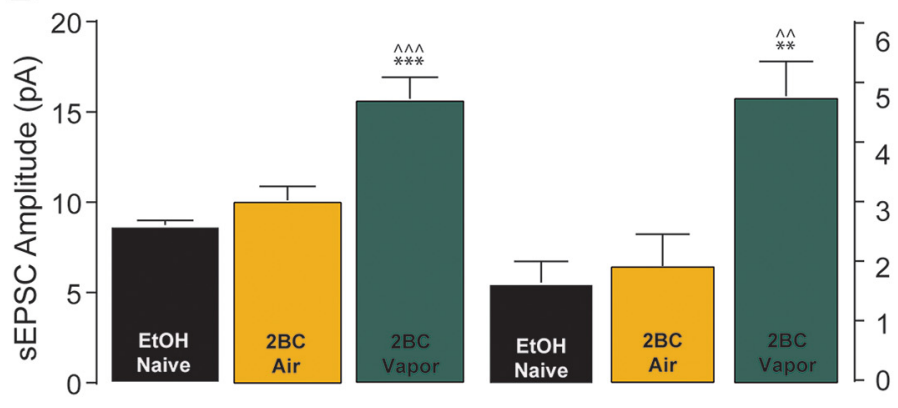

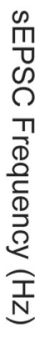
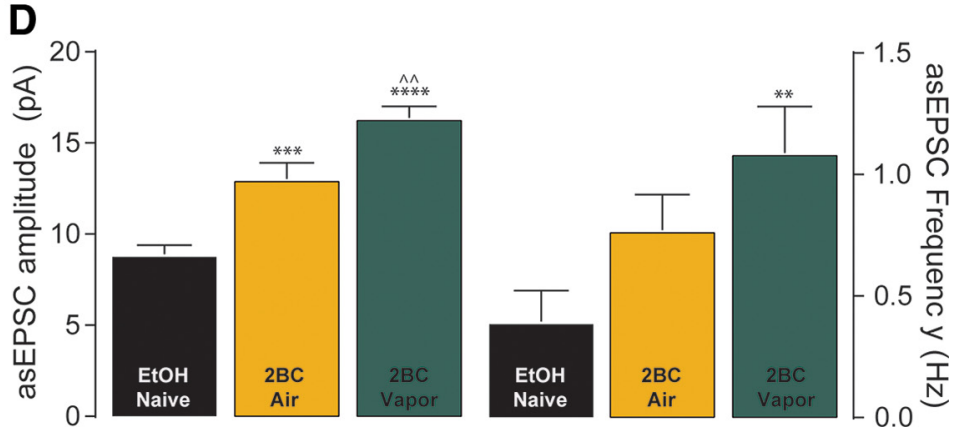

Figure 4. Ethanol experience is accompanied by enhanced glutamatergic signaling in vHipp-shNAc circuit. $\boldsymbol{A}$, Representative traces of spontaneous EPSCs. $\boldsymbol{B}, \mathrm{s}$ EPSC amplitude (ANOVA: $F_{(2,14)}=$ $39.28, p<0.0001$, Bonferroni post hoc tests: ${ }^{* * *} p<0.001$ vs naive, $\wedge \wedge \wedge p<0.001$ vs air) and frequency (ANOVA: $F_{(2,14)}=24.15, p<0.0001$, Bonferroni $p 0$ st hoc tests: ${ }^{* *} p<0.01$ vs naive, $\wedge \wedge p<0.01$ vs air) were elevated only in vapor-exposed animals (naive $n=5$ cells from 5 mice; air $n=6$ cells from 4 mice; vapor $n=6$ cells from 4 mice). $C$, Representative traces of asEPSCs; light stimulation in the presence of strontium elicit quantal like asynchronous events for a brief duration only from vHipp glutamatergic input. Red regions represent the time window where asEPSC are observed ( $30-400 \mathrm{~ms}$ after light pulse). $D$, Ethanol experience increased asEPSC amplitude (ANOVA: $F_{(2,12)}=38.85, p<0.0001$, Bonferroni $p$ ost hoc tests: ${ }^{* * *} p<0.001$ vs naive, ${ }^{* * *} p<$ 0.0001 vs naive, $\wedge \wedge p<0.01$ vs air). An increase in asEPSC frequency was only observed in vapor-exposed animals (ANOVA: $F_{(2,12)}=7.98, p<0.01$, Bonferroni $p o s t h o c$ test: ${ }^{* *} p<0.01$ vs naive; $n=5$ cells from 5 mice for all groups).

AMPAR selective antagonist NASPM. We observed a significant reduction in oEPSC amplitudes in the presence of NASPM (Fig. $6 C, D)$ in both air- and vapor-exposed mice. Together, these results indicate that the reduction in the RI observed after ethanol consumption is due to the insertion of Ca-permeable AMPARs.

\section{Discussion}

Here, we used pathway-specific optogenetics to focus exclusively on plasticity in the vHipp-NAc circuitry in response to low and high alcohol drinking. We discovered that alcohol exposure enhanced excitatory synaptic transmission by reducing LTD, enhancing presynaptic release activity, and upregulating postsynaptic Ca-permeable AMPARs, with many of these enhancements present in both the low alcohol drinking (2BC:Air) and the high alcohol drinking (2BC:CIE) group. We discuss these results in the context of previous findings and the possible impact on the reward pathway.

In the present study, we focused on D1-MSNs in the shNAc to determine input-specific neural adaptations produced by in vitro and in vivo ethanol exposure. Because vHipp input to the shNAc is the most robust glutamatergic input to this region (Britt et al., 2012), we examined this vHipp-shNAc circuit. We first verified that there is NMDAR-dependent LTD of optically evoked EPSCs and then determined whether plasticity of this isolated input onto D1-MSNs of the shNAc is altered by ethanol exposure. The present results confirm and extend prior work in several ways. We found that LTD was absent in vHipp-shNAc D1-MSN glutamatergic synapses following CIE. Furthermore, by including an ethanol-naive group, our experiments extend prior findings and indicate that $2 \mathrm{BC}$ drinking, which did not escalate in the Air group, alone can be sufficient to disrupt LTD — at least in the
vHipp-shNAc pathway. Presynaptic and postsynaptic adaptations in glutamate signaling from the vHipp were also observed following ethanol intake. Increases in asEPSC frequency and reductions in the PPR suggest enhancements in release from the vHipp following drinking that are further enhanced by vapor exposure. Postsynaptic signaling alterations, identified by increases in asEPSC amplitude and putative changes in AMPAR subunit expression, also were present in the ethanol-experienced groups. However, no difference in NMDA/AMPA ratio was observed between air- or vapor-exposed animals. Prior work found that ethanol vapor exposure enhanced the NMDA/AMPA ratio and promoted NMDAR function in D1-MSNs (Renteria et al., 2017). Therefore, the enhancement in AMPAR activity that we observed here was likely accompanied by an enhancement in NMDAR activity, resulting in no observable difference in the NMDA/AMPA ratio between the two ethanol-exposed groups. Finally, we observed evidence of the insertion of GluA2-lacking, Ca-permeable, AMPARs into vHipp-shNAc synapses following ethanol consumption, indicated by a decrease in RI and a reduction in oEPSC amplitude following application of the selective antagonist NASPM. Together, these findings indicate that chronic ethanol experience promotes vHipp glutamatergic transmission to D1-MSNs in the shNAc.

It should be noted that the ethanol-naive mice that were used for comparison with the in vivo ethanol-exposed animals were not handling controls; these mice did not receive injections, nor did they undergo chambering or tail blood collection. Therefore, comparisons of the ethanol-naive group versus the ethanolexposed groups are confounded by the fact that the $2 \mathrm{BC}$ :Air and 2BC:Vapor groups were exposed to stressors that the ethanol- 
A

\section{$\mathrm{EtOH}$}

Naive

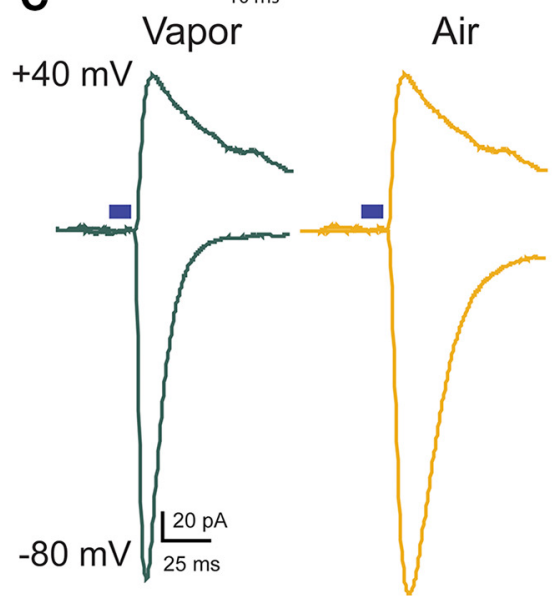

B

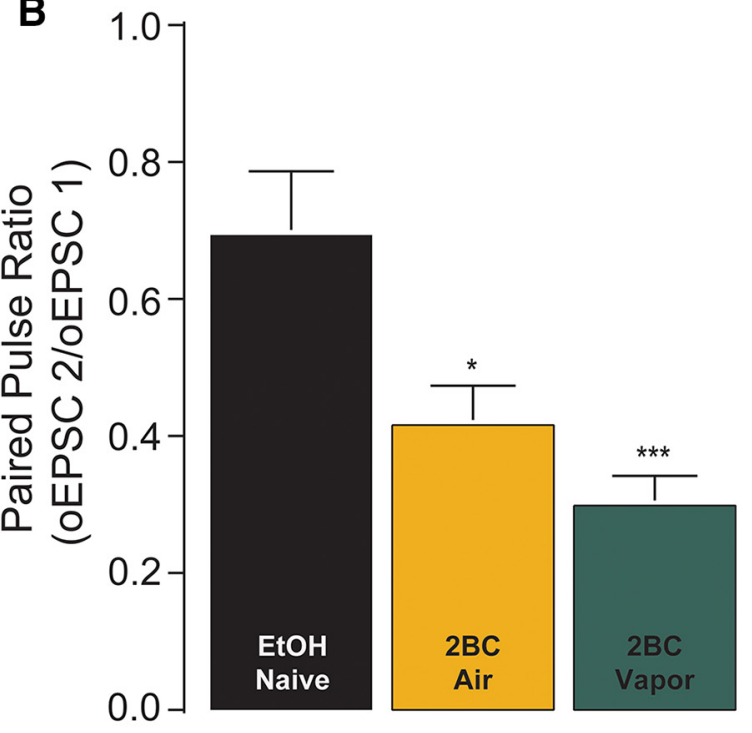

D

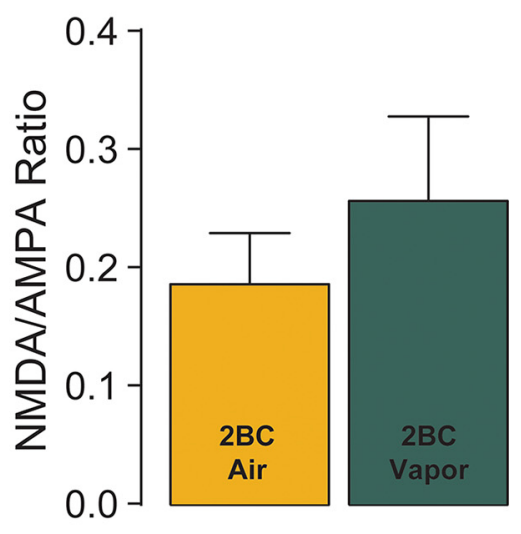

Figure 5. Presynaptic glutamatergic signaling is enhanced after ethanol experience, but CIE vapor does not affect the NMDA/AMPA ratio in $2 B C$-experienced mice. $A$, Representative traces of paired pulse $(50 \mathrm{~ms} I S I)$ recordings. $B$, Bar graphs representing PPR (second oEPSC amplitude/first oEPSC amplitude). Ethanol experience reduced the PPR with the maximum reduction in PPR observed in the vapor exposed group (ANOVA: $F_{(2,21)}=13.67,{ }^{* * *} p=0.0002$; Bonferroni post hoc tests: ${ }^{*} p<0.05$ air vs naive, ${ }^{* * *} p<0.001$ vapor vs naive; naive $n=5$ cells from 3 mice; air $n=$ 10 cells from 6 mice; vapor $n=9$ cells from 5 mice). C, Representative traces of NMDAR/AMPAR ratio recordings. The AMPAR component was elicited at $-80 \mathrm{mV}$ holding potential. The NMDAR component was elicited at a +40 holding potential and measured at $50 \mathrm{~ms}$ after stimulus offset to allow for decay of any AMPAR-mediated current. $\boldsymbol{D}$, Bar graphs representing the NMDAR/AMPAR ratio (NMDAR-mediated EPSC amplitude/AMPAR-mediated EPSC amplitude). No difference was observed in this ratio between the two groups; Student's $t$ test: $t_{(17)}=0.7689 p=0.45 ;$ air $0.186 \pm$ 0.04 , vapor $0.25 \pm 0.07$; air $n=8$ cells from 6 mice; vapor 11 cells from 6 mice).

naive group was not. In other words, we cannot rule out the possibility that the chambering procedure itself contributed to the observed phenotypes rather than ethanol experience alone. Nonetheless, we argue that the data are consistent with ethanol exposure being the relevant factor underlying the observed enhancements in glutamatergic transmission. If experimental handling, which was essentially identical between the 2BC:Air and 2BC:Vapor groups, was the primary cause of glutamatergic adaptations rather than ethanol exposure, then no differences between these two groups would be expected. However, for nearly every adaptation, the Air group mean was an intermediate value between the ethanol-naive and Vapor group means, a pattern that is consistent with group differences being related to the amount of ethanol exposure. Only the measures indicative of increases in Ca-permeable AMPARs did not exhibit this pattern. However, even a single exposure to ethanol can be sufficient to promote an increase in GluA2-lacking, Ca-permeable AMPARs at glutamatergic synapses on shNAc D1-MSNs (Beckley et al., 2016). Therefore, we propose that the lack of an intermediate effect on AMPAR composition in the Air group could be attributable to the high sensitivity of this phenomenon to ethanol.

Moreover, it is of particular interest that, in the Air group, ethanol consumption showed a strong negative correlation with the observed magnitude of LTD, suggesting that in higher drinking animals there is a corresponding adaptation in plasticity (i.e., metaplasticity) within D1-MSNs of the vHipp-shNAc pathway that shifts these neurons away from the ability to express synaptic depression. This observation is consistent with a prior report of a similar relationship between volitional ethanol consumption and LTD magnitude in shNAc D1-MSNs after operant selfadministration experience (Mangieri et al., 2017). Although there was not a significant correlation between plasticity and consumption within the Vapor group, this group exhibited a more pronounced metaplasticity in that the ability to elicit LTD in 
A

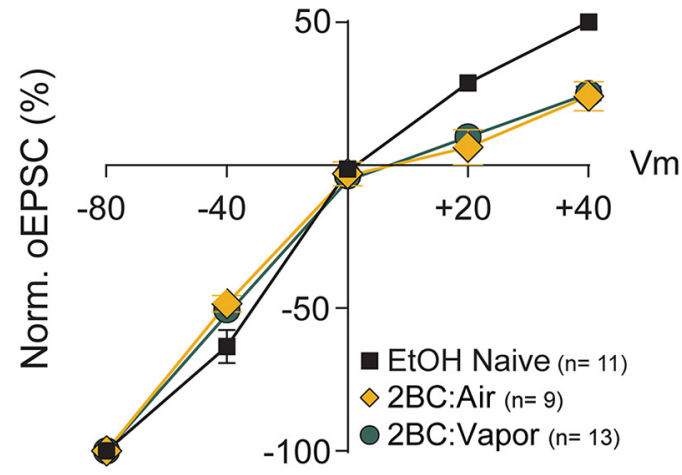

C

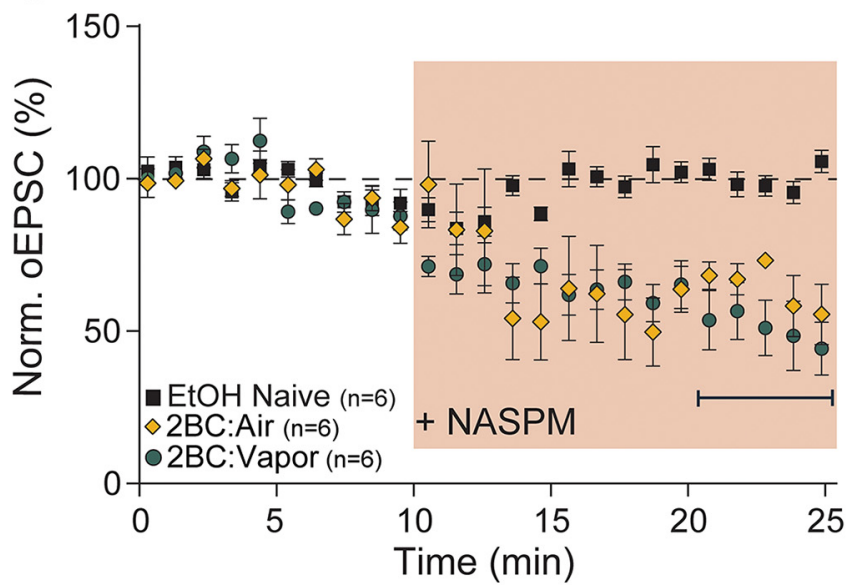

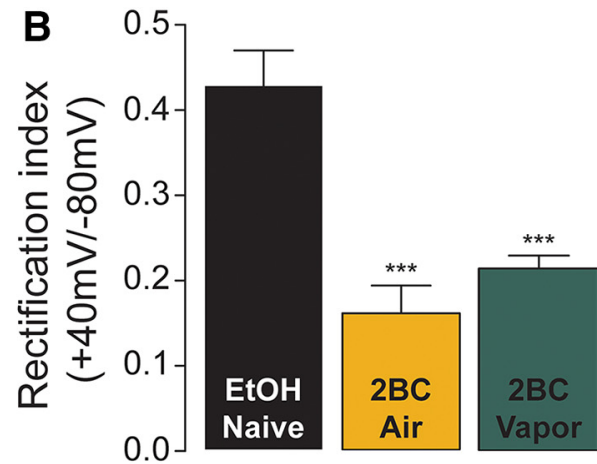

D

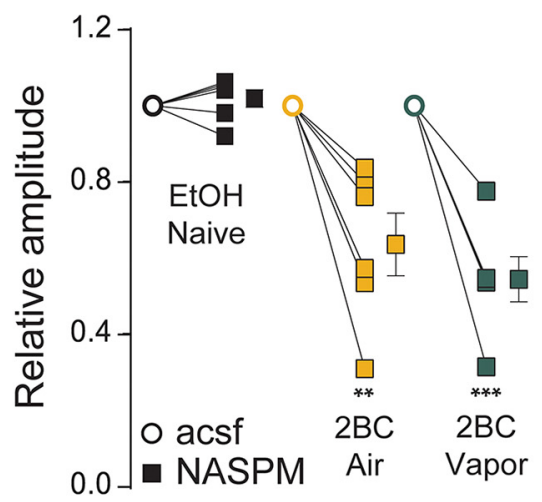

Figure 6. Insertion of Ca-permeable AMPARs into vHipp-shNAc synapses of ethanol-experienced mice. $\boldsymbol{A}$, Current-voltage relationship of AMPAR-mediated EPSCs (in the presence of D-APV) in vHipp-shNAc D1-MSNs. Twenty-four hours after drinking, a significant inward rectification is observed in ethanol-experienced animals but not naive animals ( naive $n=11$ cells from 5 mice; air $n=$ 9 cells from 6 mice; vapor $n=13$ cells from 7 animals). B, RI (EPSC amplitude at $+40 \mathrm{mV} /$ EPSC amplitude at $-80 \mathrm{mV}$ ) is decreased in both vapor- and air exposed groups $24 \mathrm{~h}$ after drinking (ANOVA: $F_{(2,30)}=20.99, p<0.0001$; Bonferroni post hoc test ${ }^{* *} p<0.001$ air or vapor vs naive). $C$, Bath application of the (a-permeable AMPAR selective antagonist NASPM produced a reduction in EPSC amplitudes in both air- and vapor-exposed animals. $D$, Averaged relative amplitudes of EPSCs before and after washing on NASPM (ANOVA: $F_{(2,15)}=17.51, p<0.0001 ;$ Bonferroni post hoc tests: ${ }^{* *} p<0.01$ vs naive, ${ }^{* * *} p<0.001$ vs naive; mean relative amplitude \pm SEM following NASPM, average of final 5 min: Et0H naive: $1.02 \pm 0.02$, air: $0.64 \pm 0.08$, vapor: $0.54 \pm 0.06 ; n=6$ cells from 6 animals for all groups).

vHipp-shNAc synapses on D1-MSNs was abolished. Therefore, the additional experience of ethanol vapor exposure likely accounts for the lack of a strong relationship between volitional consumption and plasticity in the Vapor group. Indeed, plotting the extent of LTD (or LTP) for all three groups (Naive, Air, and Vapor) as a function of ethanol consumption revealed a strong, linear relationship between ethanol exposure and plasticity of vHipp-shNAc glutamatergic synapses. In sum, these findings show that chronic exposure to increasing quantities of ethanol is associated with synaptic attenuation and enhanced vHipp excitatory synaptic input to shNAc D1-MSNs in a manner dependent on the level of exposure.

In both 2BC:Air and 2BC:Vapor mice, we demonstrate an increase Ca-permeable AMPARs relative to ethanol-naive mice, which is likely produced by ethanol consumption. In many brain regions, AMPAR activity is largely or solely mediated through GluA2-subunit-containing AMPARs, with some cells having basal Ca-permeable AMPAR activity (Conrad et al., 2008; Reimers et al., 2011; McGee et al., 2015). The subunit composition of Ca-permeable AMPARs confers faster onset and offset kinetics and substantially increases the single-channel conductance. The calcium permeability of these channels is also known to have critical functional consequences on the synapse following their expression (Henley and Wilkinson, 2013; Wu et al., 2017). Numerous types of drug exposure have been found to increase $\mathrm{Ca}-$ permeable AMPARs within the NAc D1-MSNs. Ca-permeable AMPAR insertion in D1-MSNs has been reported following exposure to cocaine (Terrier et al., 2016) or opiates (Russell et al., 2016) and following alcohol drinking (Beckley et al., 2016) or vapor exposure (Renteria et al., 2018). Enhancements in Capermeable AMPARs with the shNAc following alcohol (Beckley et al., 2016) and cocaine (James et al., 2014) exposure appear to be dependent on mTORC1 signaling and disrupting mTORC1 signaling in the NAc suppresses ethanol and cocaine seeking (Neasta et al., 2010; James et al., 2014). Together, these findings suggest that insertion of Ca-permeable AMPARs in D1-MSNs of the shNAc is critical for drug-related behaviors. Therefore, drug-induced expression of Ca-permeable AMPARs may represent a common mechanism by which repeated drug exposure and withdrawal can regulate neuronal excitability and subsequent behavior.

Our findings of enhanced glutamatergic activity in vHippD1-MSN synapses in the low-alcohol-consuming group provides a putative target for intervention that is present early in the process of the formation of dependence. Manipulations of neural transmission at this circuit during low alcohol exposure may abolish the increase in ethanol consumption following vapor exposure, thereby preventing escalation to a pathological state. This provides a potentially critical window for early intervention. If the adaptations in NAc glutamatergic signaling are indeed critical for the expression of enhanced ethanol intake, then pharmaco- 
logical or physiological manipulations during the withdrawal periods following vapor exposure should prevent the increase in ethanol intake or even reduce the amount of ethanol consumed. For example, blocking Ca-permeable AMPAR activity by infusing NASPM directly into the NAc is one possible pharmacological approach to reducing ethanol consumption, This hypothesis is supported by the finding that cocaine seeking is significantly reduced after infusing NASPM into the NAc (Schmidt et al., 2015). Another potential intervention during this window is activation of mGluR1 metabotropic glutamate receptors, which are involved in ethanol drinking behaviors (Cozzoli et al., 2012, 2014). mGluR1 can be engaged by stimulating glutamatergic terminals in the NAc at $13 \mathrm{~Hz}$, eliciting mGluR1-dependent LTD resulting in the removal of Ca-permeable AMPARs, which reverses cocaine-induced expression of Ca-permeable AMPARs and abolishes cue-induced cocaine seeking (Pascoli et al., 2014). If this approach were to successfully reverse the expression of Ca-permeable AMPARs and abolish cue-induced ethanol seeking, it would further indicate mGluR1 as a promising candidate for pharmacological intervention for alcohol dependence and alcohol use disorders.

Here, we have used optogenetic tools to demonstrate alterations in glutamatergic signaling from the vHipp to the NAc shell following ethanol consumption and the escalation in ethanol intake following CIE vapor exposure. Our findings provide further evidence that the insertion of Ca-permeable AMPARs following repeated drug exposure, documented by many other groups, also occurs following repeated alcohol consumption and highlight this phenomenon as a target for intervention.

\section{References}

Abrahao KP, Ariwodola OJ, Butler TR, Rau AR, Skelly MJ, Carter E, Alexander NP, McCool BA, Souza-Formigoni ML, Weiner JL (2013) Locomotor sensitization to ethanol impairs NMDA receptor-dependent synaptic plasticity in the nucleus accumbens and increases ethanol selfadministration. J Neurosci 33:4834-4842.

Ade KK, Wan Y, Chen M, Gloss B, Calakos N (2011) An improved BAC transgenic fluorescent reporter line for sensitive and specific identification of striatonigral medium spiny neurons. Front Syst Neurosci 5:32.

Becker HC, Lopez MF (2004) Increased ethanol drinking after repeated chronic ethanol exposure and withdrawal experience in C57BL/6 mice. Alcohol Clin Exp Res 28:1829-1838.

Beckley JT, Laguesse S, Phamluong K, Morisot N, Wegner SA, Ron D (2016) The first alcohol drink triggers mTORC1-dependent synaptic plasticity in nucleus accumbens dopamine D1 receptor neurons. J Neurosci 36:701713.

Brebner K, Wong TP, Liu L, Liu Y, Campsall P, Gray S, Phelps L, Phillips AG, Wang YT (2005) Nucleus accumbens long-term depression and the expression of behavioral sensitization. Science 310:1340-1343.

Britt JP, Benaliouad F, McDevitt RA, Stuber GD, Wise RA, Bonci A (2012) Synaptic and behavioral profile of multiple glutamatergic inputs to the nucleus accumbens. Neuron 76:790-803.

Conrad KL, Tseng KY, Uejima JL, Reimers JM, Heng LJ, Shaham Y, Marinelli M, Wolf ME (2008) Formation of accumbens GluR2-lacking AMPA receptors mediates incubation of cocaine craving. Nature 454:118-121.

Cozzoli DK, Courson J, Caruana AL, Miller BW, Greentree DI, Thompson $\mathrm{AB}$, Wroten MG, Zhang PW, Xiao B, Hu JH, Klugmann M, Metten P, Worley PF, Crabbe JC, Szumlinski KK (2012) Nucleus accumbens mGluR5-associated signaling regulates binge alcohol drinking under drinking-in-the-dark procedures. Alcohol Clin Exp Res 36:1623-1633.

Cozzoli DK, Courson J, Wroten MG, Greentree DI, Lum EN, Campbell RR, Thompson AB, Maliniak D, Worley PF, Jonquieres G, Klugmann M, Finn DA, Szumlinski KK (2014) Binge alcohol drinking by mice requires intact group 1 metabotropic glutamate receptor signaling within the central nucleus of the amygdala. Neuropsychopharmacology 39:435444.

Cull-Candy S, Kelly L, Farrant M (2006) Regulation of Ca2+-permeable
AMPA receptors: synaptic plasticity and beyond. Curr Opin Neurobiol $16: 288-297$.

Fitzpatrick CJ, Creeden JF, Perrine SA, Morrow JD (2016) Lesions of the ventral hippocampus attenuate the acquisition but not expression of sign-tracking behavior in rats. Hippocampus 26:1424-1434.

French SJ, Totterdell S (2002) Hippocampal and prefrontal cortical inputs monosynaptically converge with individual projection neurons of the nucleus accumbens. J Comp Neurol 446:151-165.

Fuchs RA, Evans KA, Ledford CC, Parker MP, Case JM, Mehta RH, See RE (2005) The role of the dorsomedial prefrontal cortex, basolateral amygdala, and dorsal hippocampus in contextual reinstatement of cocaine seeking in rats. Neuropsychopharmacology 30:296-309.

Gerdeman G, Lovinger DM (2001) CB1 cannabinoid receptor inhibits synaptic release of glutamate in rat dorsolateral striatum. J Neurophysiol $85: 468-471$.

Griffin WC 3rd (2014) Alcohol dependence and free-choice drinking in mice. Alcohol 48:287-293.

Groenewegen HJ, Vermeulen-Van der Zee E, te Kortschot A, Witter MP (1987) Organization of the projections from the subiculum to the ventral striatum in the rat: a study using anterograde transport of phaseolus vulgaris leucoagglutinin. Neuroscience 23:103-120.

Hearing MC, Jedynak J, Ebner SR, Ingebretson A, Asp AJ, Fischer RA, Schmidt C, Larson EB, Thomas MJ (2016) Reversal of morphineinduced cell-type-specific synaptic plasticity in the nucleus accumbens shell blocks reinstatement. Proc Natl Acad Sci U S A 113:757-762.

Hendricson AW, Sibbald JR, Morrisett RA (2004) Ethanol alters the frequency, amplitude, and decay kinetics of Sr2+-supported, asynchronous NMDAR mEPSCs in rat hippocampal slices. J Neurophysiol 91:25682577.

Henley JM, Wilkinson KA (2013) AMPA receptor trafficking and the mechanisms underlying synaptic plasticity and cognitive aging. Dialogues Clin Neurosci 15:11-27.

James MH, Quinn RK, Ong LK, Levi EM, Charnley JL, Smith DW, Dickson PW, Dayas CV (2014) mTORC1 inhibition in the nucleus accumbens "protects" against the expression of drug seeking and "relapse" and is associated with reductions in GluA1 AMPAR and CaMKII $\alpha$ levels. Neuropsychopharmacology 39:1694-1702.

Jeanes ZM, Buske TR, Morrisett RA (2011) In vivo chronic intermittent ethanol exposure reverses the polarity of synaptic plasticity in the nucleus accumbens shell. J Pharmacol Exp Ther 336:155-164.

Jeanes ZM, Buske TR, Morrisett RA (2014) Cell type-specific synaptic encoding of ethanol exposure in the nucleus accumbens shell. Neuroscience 277:184-195.

Joffe ME, Grueter BA (2016) Cocaine experience enhances thalamoaccumbens N-methyl-D-aspartate receptor function. Biol Psychiatry 80: 671-681.

Kasanetz F, Deroche-Gamonet V, Berson N, Balado E, Lafourcade M, Manzoni O, Piazza PV (2010) Transition to addiction is associated with a persistent impairment in synaptic plasticity. Science 328:1709-1712.

Kirk RE (1982) Procedures for testing hypotheses about means: Rules governing the choice of error term for simple effects means and simple main effects. In: Experimental design: procedures for the behavioral sciences, Ed 2, pp 509-510. Belmont, CA: Brooks Cole Publishing.

Lasseter HC, Xie X, Ramirez DR, Fuchs RA (2010) Sub-region specific contribution of the ventral hippocampus to drug context-induced reinstatement of cocaine-seeking behavior in rats. Neuroscience 171:830-839.

LeGates TA, Kvarta MD, Tooley JR, Francis TC, Lobo MK, Creed MC, Thompson SM (2018) Reward behavior is regulated by the strength of hippocampus-nucleus accumbens synapses. Nature 564:258-262.

Loweth JA, Tseng KY, Wolf ME (2014) Adaptations in AMPA receptor transmission in the nucleus accumbens contributing to incubation of cocaine craving. Neuropharmacology 76:287-300.

Lüscher C, Malenka RC (2011) Drug-evoked synaptic plasticity in addiction: from molecular changes to circuit remodeling. Neuron 69:650-663.

Mangieri RA, Maier EY, Buske TR, Lasek AW, Morrisett RA (2017) Anaplastic lymphoma kinase is a regulator of alcohol consumption and excitatory synaptic plasticity in the nucleus accumbens shell. Front Pharmacol 8:533.

Martin D, Morrisett RA, Bian XP, Wilson WA, Swartzwelder HS (1991) Ethanol inhibition of NMDA mediated depolarizations is increased in the presence of $\mathrm{Mg} 2+$. Brain Res 546:227-234.

Martin M, Chen BT, Hopf FW, Bowers MS, Bonci A (2006) Cocaine self- 
administration selectively abolishes LTD in the core of the nucleus accumbens. Nat Neurosci 9:868-869.

McCool BA (2011) Ethanol modulation of synaptic plasticity. Neuropharmacology 61:1097-1108.

McGee TP, Bats C, Farrant M, Cull-Candy SG (2015) Auxiliary subunit GSG1 L acts to suppress calcium-permeable AMPA receptor function. J Neurosci 35:16171-16179.

Neasta J, Ben Hamida S, Yowell Q, Carnicella S, Ron D (2010) Role for mammalian target of rapamycin complex 1 signaling in neuroadaptations underlying alcohol-related disorders. Proc Natl Acad Sci USA 107:20093-20098.

O’Donnell P, Grace AA (1995) Synaptic interactions among excitatory afferents to nucleus accumbens neurons: hippocampal gating of prefrontal cortical input. J Neurosci 15:3622-3639.

Pascoli V, Turiault M, Lüscher C (2011) Reversal of cocaine-evoked synaptic potentiation resets drug-induced adaptive behaviour. Nature 481:71-75.

Pascoli V, Terrier J, Espallergues J, Valjent E, O'Connor EC, Lüscher C (2014) Contrasting forms of cocaine-evoked plasticity control components of relapse. Nature 509:459-464.

Paxinos G, Franklin KBJ (2001) The mouse brain in stereotaxic coordinates, Ed 2. San Diego: Academic.

Reimers JM, Milovanovic M, Wolf ME (2011) Quantitative analysis of AMPA receptor subunit composition in addiction-related brain regions. Brain Res 1367:223-233.

Renteria R, Jeanes ZM, Mangieri RA, Maier EY, Kircher DM, Buske TR, Morrisett RA (2016) Using in vitro electrophysiology to screen medications: accumbal plasticity as an engram of alcohol dependence. Int Rev Neurobiol 126:441-465.

Renteria R, Maier EY, Buske TR, Morrisett RA (2017) Selective alterations of NMDAR function and plasticity in D1 and D2 medium spiny neurons in the nucleus accumbens shell following chronic intermittent ethanol exposure. Neuropharmacology 112:164-171.

Renteria R, Buske TR, Morrisett RA (2018) Long-term subregion-specific encoding of enhanced ethanol intake by D1DR medium spiny neurons of the nucleus accumbens. Addict Biol 23:689-698.

Riaz S, Schumacher A, Sivagurunathan S, Van Der Meer M, Ito R (2017) Ventral, but not dorsal, hippocampus inactivation impairs reward mem- ory expression and retrieval in contexts defined by proximal cues. Hippocampus $27: 822-836$.

Rogers JL, See RE (2007) Selective inactivation of the ventral hippocampus attenuates cue-induced and cocaine-primed reinstatement of drugseeking in rats. Neurobiol Learn Mem 87:688-692.

Russell SE, Puttick DJ, Sawyer AM, Potter DN, Mague S, Carlezon WA Jr, Chartoff EH (2016) Nucleus accumbens AMPA receptors are necessary for morphine-withdrawal-induced negative-affective states in rats. J Neurosci 36:5748-5762.

Scheyer AF, Wolf ME, Tseng KY (2014) A protein synthesis-dependent mechanism sustains calcium-permeable AMPA receptor transmission in nucleus accumbens synapses during withdrawal from cocaine selfadministration. J Neurosci 34:3095-3100.

Schmidt HD, McFarland KN, Darnell SB, Huizenga MN, Sangrey GR, Cha JH, Pierce RC, Sadri-Vakili G (2015) ADAR2-dependent GluA2 editing regulates cocaine seeking. Mol Psychiatry 20:1460-1466.

Shen H, Kalivas PW (2013) Reduced LTP and LTD in prefrontal cortex synapses in the nucleus accumbens after heroin self-administration. Int J Neuropsychopharmacol 16:1165-1167.

Spiga S, Talani G, Mulas G, Licheri V, Fois GR, Muggironi G, Masala N, Cannizzaro C, Biggio G, Sanna E, Diana M (2014) Hampered long-term depression and thin spine loss in the nucleus accumbens of ethanoldependent rats. Proc Natl Acad Sci U S A 111:E3745-E3754.

Stuber GD, Britt JP, Bonci A (2012) Optogenetic modulation of neural circuits that underlie reward seeking. Biol Psychiatry 71:1061-1067.

Terrier J, Lüscher C, Pascoli V (2016) Cell-type specific insertion of GluA2lacking AMPARs with cocaine exposure leading to sensitization, cueinduced seeking, and incubation of craving. Neuropsychopharmacology 41:1779-1789.

Thomas MJ, Beurrier C, Bonci A, Malenka RC (2001) Long-term depression in the nucleus accumbens: a neural correlate of behavioral sensitization to cocaine. Nat Neurosci 4:1217-1223.

Thomas MP, Monaghan DT, Morrisett RA (1998) Evidence for a causative role of N-methyl-D-aspartate receptors in an in vitro model of alcohol withdrawal hyperexcitability. J Pharmacol Exp Ther 287:87-97.

Wu D, Bacaj T, Morishita W, Goswami D, Arendt KL, Xu W, Chen L, Malenka RC, Südhof TC (2017) Postsynaptic synaptotagmins mediate AMPA receptor exocytosis during LTP. Nature 544:316-321. 